\title{
Engineering in Services
}

\author{
George Bugliarello \\ Polytechnic University
}

Traditionally, engineering has focused on artifacts. It has done so from its early beginning in the creation of fortifications to the evolution of today's disciplines ranging from aerospace to computer engineering to bioengineering. Common to all engineering fields are skills in problem-solving, coupled with a knowledge of mathematics and the sciences.

Today, those skills are being recognized as being also useful in domains far removed from the production of artifacts. Two important examples are financial services and merchandising. These are sectors that produce a substantial fraction of our gross national product, and, in the case of financial services, a steady positive balance of payments, but have received very little attention from engineering schools.

\section{Engineering in Financial Services}

Financial services are beginning to employ engineers in growing numbers.

Basically three career paths are open to engineers in this field. The first is in the area of operations, that is the processing of financial transactions, an activity involving, e.g., telecommunications and information processing. Competitiveness in the industry is heavily dependent on efficiency in carrying out transactions and on finding ever more effective ways of reaching and serving customers. For example, the ability of the New York Stock Exchange to process today a peak of some 500 million shares a day has been critical to the Exchange's continuous primacy over other exchanges abroad. To remain competitive the Exchange is aiming at a capability of 1 billion shares a day by the year 2000, a goal requiring continuing advances in hardware, software, and telecommunications.

The second career path open to engineers in financial services is in the evaluation, modeling and design of financial transactions, from derivatives to debt instruments and equities. Engineers bring to these activities a combination of problem-solving, mathematical and software design skills, and have become, together with computer scientists, mathematicians, and other quantitative oriented scientists, the backbone of the ability of the financial industry to develop ever more sophisticated financial products.

A third and rarer opportunity for engineers is to pursue the most dynamic and risky career in the financial industry by becoming traders - usually from a background in capital markets. Trading has become an increasingly sophisticated activity favoring practitioners with a good grounding in the modeling and mathematics of finance. 
“ 1994"Pdytechnic University received a large seed grant from the Sloan Foundation to establish a: Center for Technology and Financial Services. The Center was for Polytechnic a logical academic outcome of the miversity's creation, around its Brooklyn campus, of Metrotech, a university-industry park focused primarily on the financial industry. ${ }^{1}$ Today, with some 20,000 industry employees, Metrotech is the largest urban university-industry park in the U.S.

The Center for Technology and Financial Services began offering, in the Fall of 1995, a Master's Degree in Financial Engineering, with two options: operations and capital markets. The options have a common core of courses, a set of required courses specific to each option, and a set of electives. The structure of the two options is shown in Table 1 and the topics covered in the course, Introduction to Technology and Financial Services, in Table 2. (The course is taught by a group of lecturers with senior positions in the financial industry, and is also taken as an elective by students in other university curricula.) The program is one of a handful certified to date by the International Association of Financial Engineers - the professional association of financial engineers.

-The Center is advised by a distinguished Advisory Board from the financial industry - some of whom also serve as lecturers - and is chaired by an alumnus who is a top executive in a maj or financial firm. The Center includes an extension branch, the Institute for Financial Engineering, which typically offers short 1- to 3-day courses, often at the site of firms which so require.

\section{Engineering in Merchandising}

Thus far merchandising has not attracted the attention and involvement of engineering schools. Yet it is a large, diverse, and complex sector of the economy that, like the financial sector, is being revolutionized by technology. Technology is rapidly becoming the determinant factor in the ability of merchandising firms to remain competitive and indeed survive. The profit margins in many sectors of merchandising are so thin that greater efficiency, and the ability to better attract customers through technology, have become crucial.

Some of the challenges in merchandising are of the same nature of those encountered in manufacturing, such as just in time supplies, or problems of optimal warehouse siting. Other challenges involve telecommunications networks and information processing and are analogous to some of the challenges in financial services and in other service sectors. Other challenges yet, such as the "intelligent shelf," or the "intelligent store," or home shopping, or new forms of packaging, are more specific to the merchandising sector.

\section{The Synergy of Finance and Merchandising Technology}

The processes in finance and merchandising share a number of characteristics and at the same time complement each other. This makes it logical to prognosticate an ever closer connection between them, both operationally and strategically. The synergy already manifest, for example, in the credit card, will occur in the future on a much broader front, leading to a seamless continuum. The creation of that continuum involves two sets of engineering challenges. The first is of a technological nature - the development of new merchandisingoriented technological approaches in telecommunications, information processing, packaging, transportation and logistics, and above all, in the interactions among these technologies. The second set of challenges is of a socio-technological nature. It involves the interaction between these technologies and the human component of the financial and merchandising industry - the customers as well as the personnel who operate the industry. 
An example is the area of symbology, focused, in the simplest of terms, on the design of visual symbols (e.g., bar codes; böth one- and two-dimensional) and their reading by machine (such as lasers). The codes make it possible to attach in an inexpensive way machine-readable information to a material object, thereby keeping track-eftheobject and of the information, without separating the two. The result has been, for instance, not only to speed up check-outs at stores, but also to enhance the speed and reliability of the shipment of goods, to have reliable inventory management, to keep track of paperwork and to provide sophisticated identification documents. Eventually, it may also be possible to enhance the speed of the manufacturing process (e.g., assemblies), and make possible new forms of shopping.

The technology involved in every one of these aspects offers opportunities for engineering schools, both in teaching and research. To respond to the opportunities the schools need, however, to think interdisciplinarily - combining the skills of electronic engineers, physicists, mechanical engineers, industrial engineers, mathematicians and computer scientists - and to collaborate with the merchandising groups in business schools. They also need to establish close contacts with the merchandising industry.

\section{$\underline{\text { References }}$}

1. Bugliarello, George, "MetroTech: An Urban, University-Industry Park," The Journal of Urban Technology, ' R.E. Hanley, cd., New York City Technical College, Vol. 1, No. 2, Spring 1993, pp. 41-48.

\section{Acknowledgements}

The Alfred P. Sloan Foundation, Michael Corey, Treasurer, Morgan Guaranty Trust Co., Paul Soros, Paul Soros Investments, J.P. Morgan \& Co., Inc., as well as members of the Center's Advisory Board, generously provided seed and program money and advice for the establishment of the Center for Technology and Financial Services at Polytechnic University, and Stewart Nagler, Senior Executive Vice President and Chief Financial Officer of Metropolitan Life, encouragement and advice. Dr. Andrew Kalotay, Director of the Center for Technology and Financial Services, Dr. John Marshall, Director of the Financial Engineering Institute within the Center for Technology and Financial Services and Executive Director of the International Association of Financial Engineers, and Dr. Michael Dorigan, Assistant Director of the Center, have created the Center's academic programs and provided me with valuable knowledge.

Similarly, in the area of merchandising, I would like to acknowledge the advice of Arthur Martinez, Chairman and Chief Executive Officer, and of Joseph Smialowski, Vice President and Chief Information Officer, Sears Roebuck \& Co. Dr. Jerome Swartz, Chairman and Chief Executive Officer, Symbol Technologies, Inc., introduced me to the world of symbology, of which he is a major pioneer.

\section{Author's Biographical Information}

GEORGE BUGLIARELLO

Fellow of the ASCE and Chancellor of Polytechnic University of which he was president from 1973 to 1994 ; member of the NAE; has chaired the Advisory Comm. for Science and Engineering Educ. of the NSF, was a member of the Board on Engineering Educ. of the NRC, and was honored by ENR (construction) in recognition of the creation of Metrotech; holds a SC.D. from MIT and several honorary degrees. 


\section{Table 1 -MS in Financial Engineering}

\section{Core Courses}

- - -Introduction to Technology and

Financial Services

- Financial Theory and Corporate Policy

- Fixed Income Markets and Analytics

- Derivatives: Futures, Options, Swaps

. Financial Accounting

- Elements of Probability and Stochastic

Process

. Commercial Data Processing Systems

Design

$\underline{\text { Required Courses }}$

Capital Markets Option

- Linear and Nonlinear Programming

- Applied Statistics

- Numerical Methods

- Programming in $\mathrm{C}$

- Portfolio Theory and Risk Management

- Financial Engineering (Research Course)

- Special Topics: Continuous Time

- Mathematics in Finance

- Electives (6 credits)

Operations Option

. Fundamentals of Computer Science

. Design and Analysis of Algorithms

- Software Engineering I

- Principles of Database Systems

- Special Topics: Object Oriented

- Programming and $\mathrm{C}++$

- Principles of Communications Networks

- Communications Networks I

- Financial Engineering (Research Course)

- Elective (3 credits)
Electives

(1) Appropriate for Capital Markets

(2) Appropriate for Operations

Full-semester 3.0 Credit Electives

- Managerial Economics $(1,2)$

- Economics of Information Systems $(1,2)$

- Management of Communications Networks and Security $(1,2)$

- Analysis \& Design of Management Information Systems $(1,2)$

- Strategic Management $(1,2)$

- Software Engineering I (1)

- Principles of Database Systems (1)

- Operating Systems $(1,2)$

- Expert Systems and Knowledge Engineering $(1,2)$

- Neural Network Computing $(1,2)$

- Network Management \& Computing $(1,2)$

- Selected Topics in Computer Science $(1,2)$

- Object Oriented Programming (1)

- Principles of Communication Networks (1)

- Special Topics: Transactions Processing (2)

- Financial Statement Analysis $(1,2)$

- Derivatives: Advanced Applications \& Analysis (1)

- Accounting for Financial Products $(1,2)$

- International Finance (1)

- Special Topics in Financial Engineering $(1,2)$

1.5 Credit Electives (Half Semester)

. Investment Banking \& Brokerage $(1,2)$

. Financial Market Regulation $(1,2)$

- Credit Risk Measurement \& Management $(1,2)$

- Mortgage-Backed Securities (1, 2)

- Special Topics in Financial Engineering $(1,2)$ 
Table 2- Introduction to Technology and Financial Services

Weekly Topic

- Integrated Fixed Income Technology

- The United States Check Payment System

- An Overview of Derivatives

- Index World

- Microstructure of the Futures \& Options Markets

- Stock Exchanges

- Investment Banking

- Financial Engineering: Its Role in Wall Street

- The Federal Reserve Payment Services

- Securitization Process and Risk Transfer

- Ratings: How They Are Determined and Used in Capital Markets. The Role of Rating Agencies.

- Financial Information Networks 